\title{
Co-morbid psychiatric disorders among incarcerated ADHD populations: a meta-analysis
}

\author{
S. Young ${ }^{1,2 *}$, O. Sedgwick ${ }^{2,3}$, M. Fridman ${ }^{4}$, G. Gudjonsson ${ }^{3}$, P. Hodgkins ${ }^{5}$, M. Lantigua ${ }^{6}$ and \\ R. A. González ${ }^{1,6}$ \\ ${ }^{1}$ Centre for Mental Health, Division of Brain Sciences, Department of Medicine, Imperial College, London, UK \\ ${ }^{2}$ Broadmoor Hospital, West London Mental Health Trust, London, UK \\ ${ }^{3}$ Department of Psychology, Institute of Psychiatry, Psychology and Neuroscience, King's College London, London, UK \\ ${ }^{4}$ AMF Consulting Inc., Los Angeles, CA, USA \\ ${ }^{5}$ Global Health Economics \& Outcomes Research, Vertex Pharmaceuticals, Boston, MA, USA \\ ${ }^{6}$ Center for Evaluation and Sociomedical Research, Graduate School of Public Health, University of Puerto Rico, Puerto Rico
}

Background. Rates of psychiatric disorders are highly prevalent among prison inmates, and recent evidence confirms over-representation of youths and adults with attention deficit hyperactivity disorder (ADHD). The risk for psychiatric co-morbidity may be greater among offenders with ADHD. We undertook a systematic review and meta-analysis of reported rates of co-existing psychiatric morbidity with ADHD in prison samples.

\begin{abstract}
Method. Studies published from 1980 to 2015 were identified using five bibliographic indexes, review articles and reference lists. Included studies had a defined ADHD group and provided additional prevalence on at least one of the following: conduct disorder, substance use disorder, mood disorder, anxiety disorder, or personality disorder. We performed meta-analytical estimates of the prevalence of each co-morbid disorder within ADHD, and estimated the risk for co-existing disorders among prisoners with ADHD by pooling odds ratios (OR) with $95 \%$ confidence intervals.

Results. Eighteen studies with data for 1615 with ADHD and 3128 without ADHD were included. The risk (OR) of all psychiatric morbidity is increased among adult inmates with ADHD. Associations in youths with ADHD were restricted to mood disorder (OR 1.89, 95\% confidence interval 1.09-3.28).

Conclusions. This study quantifies the extent of co-morbidity presented by offenders with ADHD, especially adults. The differences between risk estimates for youths and adults indicate an incremental effect in both frequency and severity for the development of further co-morbid pathology through adulthood. The findings have implications for clinical intervention and for criminal justice policy.
\end{abstract}

Received 9 September 2015; Revised 7 March 2015; Accepted 9 March 2015; First published online 10 April 2015

Key words: ADHD, co-morbidity, meta-analysis, prison, substance use disorders.

\section{Introduction}

Attention deficit hyperactivity disorder (ADHD) is one of the most diagnosed mental health problems in children; meta-analyses estimate a world pooled prevalence of $5.3 \%$ in children and $2.5 \%$ in adults (Polanczyk et al. 2007; Simon et al. 2009). Characterized by difficulties of inattentiveness, hyperactivity and impulsivity, it is associated with significant problems in personal, social and occupational outcomes (Shaw et al. 2012). Co-morbid psychiatric problems are common presentations in both children and adults with ADHD (Pliszka, 1998) and a US nationally representative household survey found

\footnotetext{
* Author for correspondence: Dr S. Young, Centre for Mental Health, Division of Brain Sciences, Department of Medicine, Imperial College London, 37 Claybrook Road, London W6 8LN, UK.

(Email: susan.young1@imperial.ac.uk)
}

that adults with ADHD were five times more likely to develop a mood disorder, four times more likely to develop an anxiety disorder, and three times more likely to develop substance use disorder (Kessler et al. 2006). Individuals with these co-morbid disorders are likely to experience greater occupational impairment, compared to people with ADHD alone.

Compared with population rates, there is robust evidence to support an over-representation of youths and adults with ADHD in the criminal justice system, most likely reflecting high rates of co-morbidity with conduct disorder (Langley et al. 2010). A meta-analysis of 42 international studies reported that $30 \%$ and $26 \%$ of the youth and adult prison populations, respectively, had clinically diagnosed ADHD (Young et al. 2014). There were no significant differences for gender and age, which does not parallel the corresponding differences observed in the general population. With respect to age, the implication is that

This is an Open Access article, distributed under the terms of the Creative Commons Attribution licence (http://creative commons.org/licenses/by/3.0/), which permits unrestricted re-use, distribution, and reproduction in any medium, provided the original work is properly cited. 
young offenders with ADHD who come into contact with the criminal justice system remain within this system as repeat offenders.

More generally, rates of psychiatric disorders are over-represented among prisoners (Fazel \& Seewald, 2012) and it seems that the risk for developing co-morbid psychiatric disorders may be greater among offenders with ADHD (Abram et al. 2003; Einarsson et al. 2009; Young et al. 2011b; Gudjonsson et al. 2012; Gonzalez et al. 2013, 2015). The confounding effect of this high level of psychiatric co-morbidity is very likely to influence the behaviour, management and treatment of these individuals as, despite international guidelines (Seixas et al. 2012) and treatment benefits on ADHD symptoms (Shaw et al. 2012), ADHD is rarely diagnosed and treated by offender mental health teams, as concluded by a multi-agency consensus on ADHD and offender management (Young et al. 2011c). This problem needs to be addressed, especially since outcomes of treatment for ADHD may be highly effective, with both individual (Ginsberg et al. 2012) and societal gains (Lichtenstein et al. 2012).

It is therefore important to better estimate the risk of the development of co-morbid disorders (including type of disorder) among offenders with ADHD to inform healthcare practitioners, who in turn can deliver more appropriate treatment, management and care plans. Hence this study synthesized data obtained from a systematic literature search performed to ascertain the psychiatric co-morbid conditions associated with a clinical diagnosis of ADHD in both youth and adult prisoners using meta-analysis. Rates were compared with prisoners without ADHD.

\section{Method}

\section{Eligibility criteria}

The systematic review was performed in accordance with the Preferred Reporting Items for Systematic reviews and Meta-Analyses (PRISMA guidelines) (Liberati et al. 2009). Initial searches were carried out in a variety of databases and websites to gain an understanding of the amount of information available. Reports published since 1980 and in English were included.

\section{Data sources}

Searches were conducted in OvidSP Medline (1948 to present) and EMBASE (1988 to present segment), Datastar PsycINFO (unrestricted) and Social SciSearch (1972 to date; limited to English and added since 1 January 1980), including the literature published between 1 January 1980 and 3 May 2011; the search was further extended to 31 May 2014 on 25 June 2014. One additional study (Konstenius et al. 2015) was added following reviewer feedback.

\section{Search}

Search terms were developed, refined and tested for relevance by cross-checking results against a list of known relevant articles provided by the lead author. The following descriptors were utilized in OvidSP EMBASE (1988 to present segment): ADHD; attention deficit disorder; [EMTREE] crime; criminals; criminology; criminal behaviour; criminal justice; criminal law; court; criminal psychology; delinquency; juvenile delinquency; gang; legal evidence; legal procedure; police; legal liability; mandatory programs; violence; prisons; prisoner; probation; law enforcement; recidivism; jurisprudence; punishment; offender; drug abuse; drug misuse. Studies were examined to identify those containing information about co-morbid psychiatric disorders in an incarcerated ADHD population.

\section{Study selection}

Articles obtained from the final searches were first de-duplicated, then an inclusion/exclusion screening process was undertaken based on the following exclusion criteria: non-English-language articles, articles published before 1980, animal studies, articles that were not peer reviewed (e.g. dissertations), and articles that obviously did not hold relevance (e.g. they did not focus on ADHD or crime and/or contained information about co-morbid psychiatric disorders).

Review articles pre-2006 were excluded, and post2006 reviews were kept with the sole purpose to examine bibliographies to check for any other articles not identified in the search; these review articles were not included in the final prevalence calculation; only primary research articles were included. Articles with no abstract (including initial PsycINFO and Social SciSearch search outputs) were also excluded unless the title or other information (e.g. key terms) suggested they may hold relevance. The inclusion/exclusion review was first completed based on title/abstract/ key words by two researchers, and if the relevance of an article was unclear, the full text was retrieved before a final decision was made. Once the initial inclusion/ exclusion process was completed, the full texts of included articles were retrieved for detailed evaluation against eligibility criteria:

- Studies must use samples composed entirely of incarcerated individuals.

- Studies must define a clear ADHD group, i.e. give the prevalence of their sample who met diagnostic/ screening criteria for ADHD using a validated 
measure. Studies in adults which reported only retrospective self-report of childhood symptoms were not included due to the likelihood that the rates would be overinflated (Young et al. 2014).

- Studies must give additional prevalence on at least one of the following: conduct disorder, substance use disorder, mood disorder, anxiety disorder, or personality disorder. The studies must report these variables by ADHD group status (or provide information so that this can be deduced) so the characteristics can be compared between an ADHD group and a non-ADHD group from within the same sample.

\section{Data collection process}

A data extraction sheet was developed in Microsoft Excel. The full text publications were divided randomly among two researchers who performed the data extraction independently. Data were reviewed for consistency and any queries were resolved by discussion among the researchers and the lead author. The lead author also made the final decision whether to include/exclude data by reviewing the identified publications. Some cohorts of prison populations were published more than once (Retz et al. 2004; Rosler et al. 2004; Young et al. 2009, 2011b; Gudjonsson et al. 2011, 2012). To avoid double counting data, multiple reports of the same cohort were pieced together by juxtaposing author names, sample sizes and rates of co-morbidity.

\section{Data items}

For each included study, the following variables were extracted:

(1) Number of people with ADHD and the selected co-morbidities, (2) number of people without ADHD but with the selected co-morbidities, (3) number of people with ADHD but without the selected co-morbidities, (4) number of people with neither ADHD nor the co-morbidities, (5) youth/underage and adult sample, (6) sex of sample. In addition to the co-morbidities that are reported on, we attempted to obtain rates of autism spectrum disorder and learning disability, but too few papers reported on these diagnoses.

(2) It was noted that there was no clear definition across publications on the age of an adult $v$. a youth. For the purposes of this meta-analysis, we designated 18 years to be the cut-off point for a youth becoming an adult (i.e. youths were $\leqslant 18$ years and adults were $>18$ years); papers reporting youth data often cited 18 years as the upper limit of the age range of participants. In those papers where an age range was given that spanned this cut-off point (e.g. 15-28 years), the mean (or median if mean was not provided) was used to define whether the study population should be listed as 'youth' or 'adult'. For studies reporting on both genders separately, information was recorded as two separate observations ('study strata') linked by the study number.

\section{Quality control}

To ascertain the validity of eligible publications, one of the researchers checked and independently reviewed all papers selected for data extraction and interpretation consistency. Disagreements were resolved by reviewing the data source and by discussion between two reviewers.

\section{Statistical analysis}

First, pooled random effect meta-analysis estimates of the prevalence of each psychiatric disorder within participants with ADHD were computed. Second, meta-analyses of risk for co-existing disorders among prisoners with ADHD were performed calculating pooled odds ratios (OR) with $95 \%$ confidence intervals (CIs).

Considering heterogeneity of ADHD assessment in research, differences in the criminal justice population, and sample characteristics across countries, a randomeffects model approach was established a priori. A random-effects approach presupposes that studies are too dissimilar to assume they theoretically come from the same sample. Studies in each domain were pooled using the DerSimonian \& Laird (1986) method for random effects meta-analysis. Heterogeneity is reported by the $I^{2}$ index, which describes the percentage of variation across studies that is from actual heterogeneity rather than chance. The $I^{2}$ statistic does not entirely depend on the number of studies considered (Higgins \& Thompson, 2002). Values of 25, 50 and 75 respectively denote low, moderate and high heterogeneity.

We explored the risk for co-morbidity overall and by age group separately for each of the following psychiatric disorders: conduct disorder (CD), substance use disorders (SUD), mood disorders (MD), anxiety disorders (AD) and personality disorders (PD). PD was only reported for adult studies. Subgroup analysis based on gender was not possible due to the low number of studies that resulted by stratifying results for male, female and mixed samples for each co-morbid category. Abram et al. (2003) and Plattner et al. (2007) reported their data separately by gender. We combined these sources of data by performing a 'within study' meta-analysis, therefore obtaining a common standard 
error for all participants of those studies, which was then used in the overall pooled meta-analyses and meta-regressions.

Meta-regression was used to examine the impact of age (continuous) and gender (male, female, mixed) as covariates on the pooled OR calculated for co-existing disorders. All analyses were performed using Stata v. 13 (StataCorp, USA) metan and metareg commands.

\section{Results}

In total, 9410 publications were identified following the OvidSP Medline, EMBASE, Datastar, PsycINFO and Social SciSearch database search. One additional publication was added through personal communication. Publications not specifically relating to ADHD and criminality and duplicates between databases were excluded electronically, leaving 339. Once further duplicates had been identified manually, 325 publications remained for which the full text was retrieved. 281 publications were further excluded as they did not report on incarcerated ADHD samples and/or did not provide associated co-morbid disorders data.

A further 26 studies were then removed for the following reasons: (1) used inadequate methods to assess ADHD status (e.g. studies that only used retrospective symptom assessment, self-report of 'behavioural problems' as a child, no consideration of childhood symptoms before adulthood diagnosis given, ADHD and specific developmental disorder considered synonymous; nine studies), (2) provided co-morbid information but only for the whole sample, not specified by ADHD status (six studies), and (3) did not have an adequate control group (i.e. all included participants had ADHD, or the control comparison group was not incarcerated; five studies). Although data on ADHD and CD were provided, we excluded Forehand et al. (1991) from this analysis because all their cases had CD (i.e. two 0 count cells). Data from Chang et al. (2007) specific to SUD were also removed because all their cases were co-morbid with ADHD.

For those papers that presented the co-morbidity data continuously (e.g. as $T$ scores, mean scores on diagnostic screens, etc.; six authors relating to eight studies), the author was contacted to attempt to gain rates for the co-morbid diagnosis (i.e. number of participants who fulfilled clinical criteria). One author responded with additional data relating to a study conducted in Scotland (Gudjonsson et al. 2012), which was subsequently included in the meta-analysis. The remaining five studies were excluded as their data could not be meaningfully utilized.

Thus, a total of 18 studies of prisoners with/without ADHD and co-morbid disorders were selected to provide data for the meta-analysis (see Fig. 1 for a flow chart of the manual screening process). These 18 studies included nine adult and nine youth studies, for a combined sample of 1615 participants with ADHD and 3128 without the disorder (See Table 1). For each co-morbid category, pooled effects are presented by the overall sample of studies, followed by subgroup analysis for youth and adult samples.

\section{Pooled random-effects meta-analysis estimates}

Table 2 shows all pooled prevalence rates and 95\% CIs of co-morbid disorders. Among youths with ADHD, pooled prevalence rates of $\mathrm{CD}, \mathrm{SUD}, \mathrm{MD}$, depression and $\mathrm{AD}$ were $61 \%, 70 \%, 25 \%, 13 \%$ and $21 \%$, respectively. In adults with ADHD, the respective prevalence rates were $29 \%, 74 \%, 66 \%, 55 \%, 68 \%$ and $60 \%$ for personality disorders.

\section{Meta-analyses of risk for co-existing disorders}

\section{Conduct disorder}

Seven studies (Kaplan \& Cornell, 2004; Gordon \& Moore, 2005; Chang et al. 2007; Stahlberg et al. 2010; Westmoreland et al. 2010; Young et al. 2011a; Grieger \& Hosser, 2012) provided data on the association between ADHD and CD (Fig. 2a). The overall association was not significant (OR 1.16, 95\% CI 0.61-2.20). Subgroup analysis by youth and adult studies revealed no significant pooled effects for youth samples, but a significant effect based on two adult studies (OR 2.10, 95\% CI 1.19-3.70; Fig. 3a]. Heterogeneity was high in youth studies and low in adults $\left(I^{2}=77.1 v\right.$. $33.9 \%$ ).

\section{Substance use disorders}

Eleven studies (Milin et al. 1991; Abram et al. 2003; Retz et al. 2004; Gordon \& Moore, 2005; Einarsson et al. 2009; Rosler et al. 2009; Stahlberg et al. 2010; Westmoreland et al. 2010; Young et al. 2011b; Grieger \& Hosser, 2012; Konstenius et al. 2015) provided data on the association between ADHD and SUD (Fig. 2b). There was a significant overall effect size (OR 2.48, 95\% CI $1.30-4.72)$, with substantial heterogeneity $\left(I^{2}=84.3 \%\right)$. Subgroup analysis indicated a significant pooled effect for adults (OR 2.41, 95\% CI 1.22-4.79) but not for youths (OR 2.28, 95\% CI 0.73-7.12). Heterogeneity was high $\left(I^{2}=91.9 \%\right)$ in youth studies and moderate $\left(I^{2}=54.8 \%\right)$ in adults (Fig. $\left.3 b\right)$.

\section{Mood/affective disorders and depression}

Twelve studies (Eyestone \& Howell, 1994; Abram et al. 2003; Gordon \& Moore, 2005; Anckarsater et al. 2007; Chang et al. 2007; Plattner et al. 2007; Einarsson et al. 2009; Rosler et al. 2009; Stahlberg et al. 2010; 


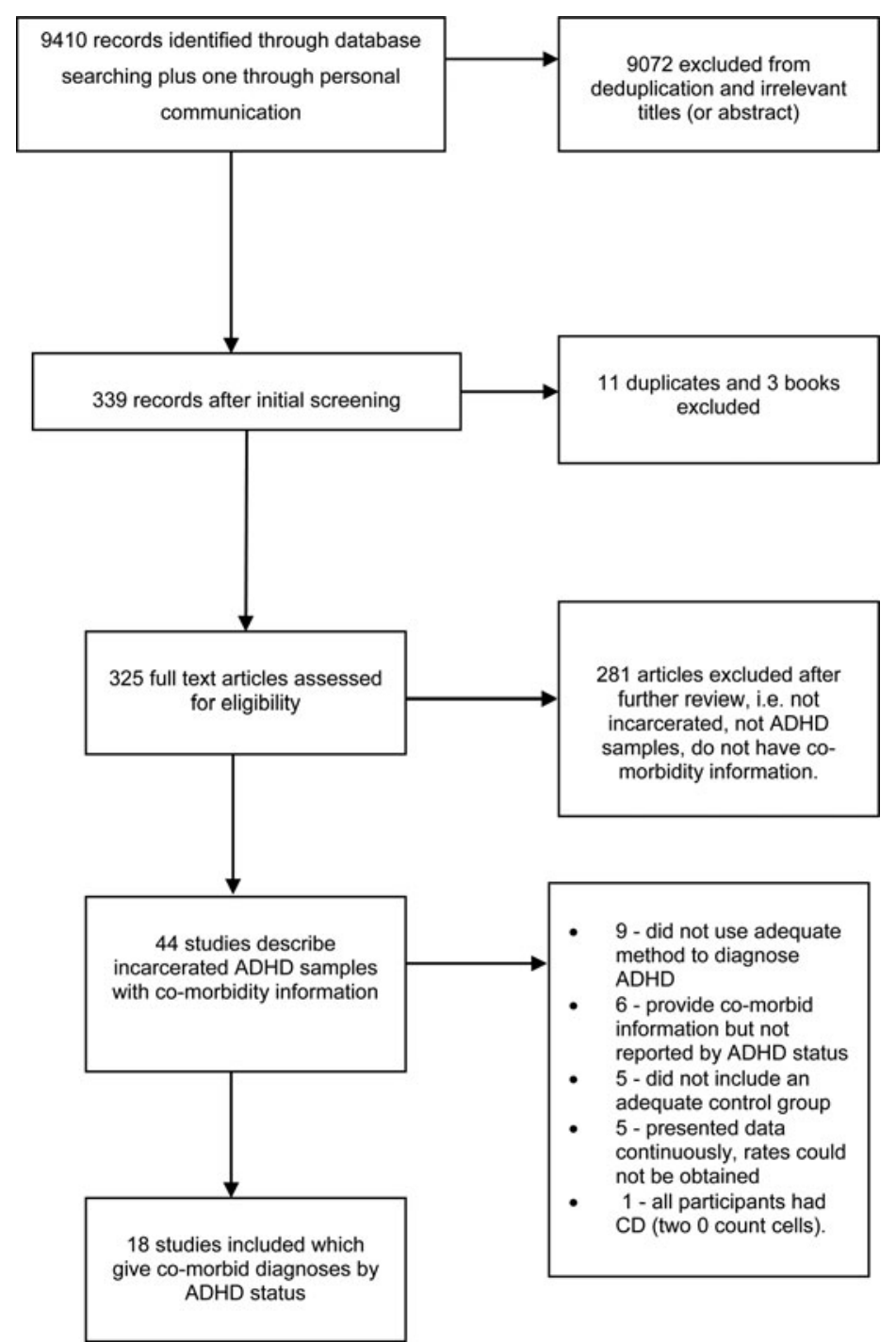

Fig. 1. Flow diagram of the manual screening process for eligible literature inclusion.

Westmoreland et al. 2010; Young et al. 2011b; Konstenius et al. 2015) provided data on mood/affective disorders, which included depression, mania and adjustment disorder with associated mood symptoms (Fig. 2c). The overall effect size was significant (OR 2.96, 95\% CI 1.86-4.71), with moderate heterogeneity $\left(I^{2}=64.2 \%, p=0.001\right)$. The pooled effect was significant for studies in youth (OR 1.89, 95\% CI 1.09-3.28) and adults (OR 4.50, 95\% CI 2.69-7.51), with low heterogeneity in both (youth $I^{2}=48.3 \%$; adults $I^{2}=39.0 \%$ ) (Fig. 3c).

To partial-out how much of the effect of mood disorders was likely due to depression, we performed a meta-analysis on nine studies (Eyestone \& Howell, 1994; Gordon \& Moore, 2005; Anckarsater et al. 2007; Chang et al. 2007; Einarsson et al. 2009; Stahlberg et al. 2010; Westmoreland et al. 2010; Young et al. 2011b; Konstenius et al. 2015) that provided data specific for depressive disorder (Fig. $2 d$ ). The overall effect size was significant (OR 3.00, 95\% CI 1.70-5.29), with moderate heterogeneity $\left(I^{2}=62.9 \%\right)$. The effect of ADHD on depression was not significant in youth participants (OR 1.59, 95\% CI 0.61-4.14) but was significant in adults (OR 4.66, 95\% CI 2.92-7.45), with moderate and no heterogeneity, respectively (youth $I^{2}=$ $57.3 \%$; adults $I^{2}=24.5 \%$ ).

\section{Anxiety disorders}

On the seven studies(Abram et al. 2003; Chang et al. 2007; Einarsson et al. 2009; Rosler et al. 2009; Stahlberg et al. 2010; Westmoreland et al. 2010; Young et al. 2011b) with data on associations between $\mathrm{ADHD}$ and $\mathrm{AD}$ (Fig. 2e), there was no significant 
Table 1. Summary of characteristics of studies included in the meta-analyses, by psychiatric disorders and pooled co-morbidity rates, by psychiatric disorders

\begin{tabular}{|c|c|c|c|c|c|c|}
\hline Study (year) & Gender & Age group & $\begin{array}{l}\text { Age } \\
(\bar{x})\end{array}$ & $\begin{array}{l}\text { ADHD/ } \\
\text { total }\end{array}$ & $\begin{array}{l}\text { Co-morbidity/ } \\
\text { total }\end{array}$ & $\begin{array}{l}\text { Co-morbidity rates/ } \\
\text { ADHD }\end{array}$ \\
\hline \multicolumn{7}{|l|}{ Conduct disorder } \\
\hline Chang et al. (2007) & Males & $\leqslant 18$ & 17.7 & $37 / 59$ & $44 / 59$ & $24 / 37$ \\
\hline Gordon \& Moore (2005) & Males & $\leqslant 18$ & 16.0 & $92 / 453$ & $247 / 453$ & $53 / 92$ \\
\hline Kaplan \& Cornell (2004) & Males & $\leqslant 18$ & 16.0 & $30 / 122$ & $52 / 122$ & $7 / 30$ \\
\hline Stahlberg et al. (2010) & Mixed & $\leqslant 18$ & 16.3 & $47 / 100$ & $77 / 100$ & $36 / 47$ \\
\hline Young et al. (2011a) & Males & $\leqslant 18$ & 14.6 & $23 / 54$ & $33 / 54$ & $19 / 23$ \\
\hline Grieger \& Hosser (2012) & Males & Adult & 19.0 & $55 / 275$ & $58 / 275$ & $15 / 55$ \\
\hline Westmoreland et al. (2010) & Mixed & Adult & 29.2 & $68 / 319$ & $56 / 319$ & $21 / 68$ \\
\hline \multicolumn{7}{|l|}{ Substance use disorders } \\
\hline Abram et al. (2003) & Males & $\leqslant 18$ & 14.0 & $524 / 1170$ & $604 / 1170$ & $387 / 524$ \\
\hline Abram et al. (2003) & Females & $\leqslant 18$ & 14.0 & $317 / 656$ & $303 / 656$ & $205 / 317$ \\
\hline Gordon \& Moore (2005) & Males & $\leqslant 18$ & 16.0 & $92 / 453$ & $351 / 453$ & $74 / 92$ \\
\hline Milin et al. (1991) & Mixed & $\leqslant 18$ & 15.5 & $21 / 111$ & $90 / 111$ & $21 / 21^{\mathrm{a}}$ \\
\hline Stahlberg et al. (2010) & Mixed & $\leqslant 18$ & 16.3 & $47 / 100$ & $55 / 100$ & $25 / 47$ \\
\hline Einarsson et al. (2009) & Males & Adult & 31.0 & $27 / 90$ & $55 / 90$ & $22 / 27$ \\
\hline Grieger \& Moore (2012) & Males & Adult & 19.0 & $55 / 275$ & $89 / 275$ & $18 / 55$ \\
\hline Konstenius et al. (2015) & Females & Adult & 39.7 & $16 / 56$ & $39 / 56$ & $16 / 16^{\mathrm{a}}$ \\
\hline Retz et al. (2004) & Males & Adult & 18.8 & $28 / 129$ & $109 / 129$ & $25 / 28$ \\
\hline Rosler et al. (2009) & Females & Adult & 34.0 & $11 / 94$ & $49 / 94$ & $9 / 11$ \\
\hline Westmoreland et al. (2010) & Mixed & Adult & 29.2 & $68 / 319$ & $286 / 319$ & $67 / 68$ \\
\hline Young et al. $(2011 b)$ & Males & Adult & 30.0 & $27 / 198$ & $108 / 198$ & $16 / 27$ \\
\hline \multicolumn{7}{|l|}{ Mood disorders } \\
\hline Abram et al. (2003) & Males & $\leqslant 18$ & 14.0 & $524 / 1170$ & $150 / 1170$ & $145 / 524$ \\
\hline Abram et al. (2003) & Females & $\leqslant 18$ & 14.0 & $317 / 656$ & $144 / 656$ & $102 / 317$ \\
\hline Anckarsater et al. (2007) & Mixed & $\leqslant 18$ & 16.2 & $51 / 130$ & $17 / 130$ & $4 / 51$ \\
\hline Chang et al. (2007) & Males & $\leqslant 18$ & 17.7 & $37 / 59$ & $6 / 59$ & $5 / 37$ \\
\hline Gordon \& Moore (2005) & Males & $\leqslant 18$ & 16.0 & $92 / 453$ & $148 / 453$ & $39 / 92$ \\
\hline Plattner et al. (2007) & Males & $\leqslant 18$ & 16.5 & $108 / 266$ & $50 / 266$ & $29 / 108$ \\
\hline Plattner et al. (2007) & Females & $\leqslant 18$ & 17.8 & $17 / 53$ & $19 / 53$ & $8 / 17$ \\
\hline Stahlberg et al. (2010) & Mixed & $\leqslant 18$ & 16.3 & $47 / 100$ & $20 / 100$ & $14 / 47$ \\
\hline Einarsson et al. (2009) & Males & Adult & 31.0 & $27 / 90$ & $29 / 90$ & $13 / 27$ \\
\hline Eyestone \& Howell (1994) & Males & Adult & 40.0 & $48 / 88$ & $49 / 88$ & $38 / 48$ \\
\hline Konstenius et al. (2015) & Females & Adult & 39.7 & $16 / 56$ & $24 / 56$ & $9 / 16$ \\
\hline Rosler et al. (2009) & Females & Adult & 34.0 & $11 / 94$ & $53 / 94$ & $8 / 11$ \\
\hline Westmoreland et al. (2010) & Mixed & Adult & 29.2 & $68 / 319$ & $173 / 319$ & $59 / 68$ \\
\hline Young et al. $(2011 b)^{\mathrm{b}}$ & Males & Adult & 30.0 & $27 / 196$ & $38 / 196$ & $12 / 27$ \\
\hline \multicolumn{7}{|l|}{ Depressive disorder } \\
\hline Anckarsater et al. (2007) & Mixed & $\leqslant 18$ & 16.2 & $51 / 130$ & $17 / 130$ & $4 / 51$ \\
\hline Chang et al. (2007) & Males & $\leqslant 18$ & 17.7 & $37 / 59$ & $6 / 59$ & $5 / 37$ \\
\hline Gordon \& Moore (2005) & Males & $\leqslant 18$ & 16.0 & $86 / 436$ & $20 / 436^{c}$ & $6 / 86$ \\
\hline Stahlberg et al. (2010) & Mixed & $\leqslant 18$ & 16.3 & $47 / 100$ & $20 / 100$ & $14 / 47$ \\
\hline Einarsson et al. (2009) & Males & Adult & 31.0 & $27 / 90$ & $19 / 90$ & $9 / 27$ \\
\hline Eyestone \& Howell (1994) & Males & Adult & 40.0 & $48 / 88$ & $49 / 88$ & $38 / 48$ \\
\hline Konstenius et al. (2015) & Females & Adult & 39.7 & $16 / 56$ & $24 / 56$ & $9 / 16$ \\
\hline Westmoreland et al. (2010) & Mixed & Adult & 29.2 & $68 / 319$ & $74 / 319$ & $34 / 68$ \\
\hline Young et al. $(2011 b)^{\mathrm{b}}$ & Males & Adult & 30.0 & $27 / 196$ & $21 / 196$ & $8 / 27$ \\
\hline \multicolumn{7}{|l|}{ Anxiety disorders } \\
\hline Abram et al. (2003) & Males & $\leqslant 18$ & 14.0 & $524 / 1170$ & $230 / 1170$ & $182 / 524$ \\
\hline Abram et al. (2003) & Females & $\leqslant 18$ & 14.0 & $317 / 656$ & $206 / 656$ & $126 / 317$ \\
\hline Chang et al. (2007) & Males & $\leqslant 18$ & 17.7 & $37 / 59$ & $15 / 59$ & $5 / 37$ \\
\hline Stahlberg et al. (2010) & Mixed & $\leqslant 18$ & 16.3 & $47 / 100$ & $18 / 100$ & $6 / 47$ \\
\hline Einarsson et al. (2009) & Males & Adult & 31.0 & $27 / 90$ & $24 / 90$ & $11 / 27$ \\
\hline
\end{tabular}


Table 1 (cont.)

\begin{tabular}{|c|c|c|c|c|c|c|}
\hline Study (year) & Gender & Age group & $\begin{array}{l}\text { Age } \\
(\bar{x})\end{array}$ & $\begin{array}{l}\mathrm{ADHD} / \\
\text { total }\end{array}$ & $\begin{array}{l}\text { Co-morbidity/ } \\
\text { total }\end{array}$ & $\begin{array}{l}\text { Co-morbidity rates/ } \\
\text { ADHD }\end{array}$ \\
\hline Rosler et al. (2009) & Females & Adult & 34.0 & $11 / 94$ & $50 / 94$ & $8 / 11$ \\
\hline Westmoreland et al. (2010) & Mixed & Adult & 29.2 & $68 / 319$ & $136 / 319$ & $46 / 68$ \\
\hline Young et al. $(2011 b)$ & Males & Adult & 30.0 & $27 / 198$ & $120 / 198$ & $24 / 27$ \\
\hline \multicolumn{7}{|l|}{ Personality disorders ${ }^{\mathrm{d}}$} \\
\hline Black et al. (2004) & Mixed & Adult & 30.7 & $68 / 320$ & $113 / 320$ & $37 / 68$ \\
\hline Einarsson et al. (2009) & Males & Adult & 31.0 & $27 / 90$ & $52 / 90$ & $23 / 27$ \\
\hline Konstenius et al. (2015) & Females & Adult & 39.7 & $16 / 56$ & $25 / 56$ & $13 / 16$ \\
\hline Retz et al. (2004) & Males & Adult & 18.8 & $28 / 129$ & $27 / 129$ & $6 / 28$ \\
\hline Rosler et al. (2009) & Females & Adult & 34.0 & $11 / 94$ & $28 / 94$ & $7 / 11$ \\
\hline Westmoreland et al. (2010) & Mixed & Adult & 29.2 & $68 / 319$ & $112 / 319$ & $37 / 68$ \\
\hline Young et al. $(2011 b)$ & Males & Adult & 30.0 & 27/198 & $141 / 198$ & $24 / 27$ \\
\hline
\end{tabular}

ADHD, Attention deficit hyperactivity disorder

${ }^{a}$ Not included in the meta-analytic prevalence rate because of one 0 count cell.

${ }^{\mathrm{b}}$ There were two missing cases on these co-morbidity rates.

${ }^{\mathrm{c}} 17$ cases excluded as questionable depression.

${ }^{\mathrm{d}}$ Only adult studies included.

Table 2. Pooled random effects meta-analysis estimates of the prevalence of psychiatric disorders co-existing with ADHD

\begin{tabular}{|c|c|c|c|c|}
\hline \multirow[b]{2}{*}{ Psychiatric co-morbidity } & \multicolumn{2}{|c|}{$\leqslant 18$ years } & \multicolumn{2}{|c|}{ Adults } \\
\hline & Rate & $95 \%$ CI & Rate & $95 \% \mathrm{CI}$ \\
\hline Conduct disorder & 0.61 & $0.43-0.80$ & 0.29 & $0.21-0.37$ \\
\hline Substance use disorders & 0.70 & $0.59-0.80$ & 0.74 & $0.52-0.96$ \\
\hline Mood disorders & 0.25 & $0.16-0.34$ & 0.66 & $0.50-0.81$ \\
\hline Depressive disorder & 0.13 & $0.05-0.21$ & 0.55 & $0.35-0.76$ \\
\hline Anxiety disorders & 0.21 & $0.03-0.40$ & 0.68 & $0.48-0.88$ \\
\hline Personality disorders ${ }^{a}$ & - & - & 0.60 & $0.41-0.78$ \\
\hline
\end{tabular}

ADHD, Attention deficit hyperactivity disorder; CI, confidence interval.

${ }^{a}$ Only adult studies included.

overall effect (OR 1.82, 95\% CI 0.78-4.28; $I^{2}=79.3 \%$ ). Stratification revealed no effect in youth studies (OR $0.72,95 \%$ CI $0.13-3.95 ; I^{2}=84.9 \%$ ), but was significant among adults (OR 3.58, 95\% CI 2.32-5.53), with no heterogeneity (Fig. 3e).

\section{Personality disorders}

Only studies in adults (Black et al. 2004; Retz et al. 2004; Einarsson et al. 2009; Rosler et al. 2009; Westmoreland et al. 2010; Young et al. 2011b; Konstenius et al. 2015) were considered for the effect size of the association with PD (Fig. 2f). Seven studies showed a significant overall effect of ADHD in PD (OR 3.22, 95\% CI 2.075.01) with low heterogeneity $\left(I^{2}=37.6 \%\right)$.
Meta-regression. To further assess potential sources of heterogeneity, the effect size (OR) of each co-morbid category was regressed on age and gender. Age was significantly $(p<0.05)$ associated with an increase in the OR between ADHD and mood/affective disorders including depression. Age was not a significant factor on the remaining co-morbid categories. There were no effects of gender on any of the effect sizes. The latter result might be a reflection of low power to detect differences in addition to a potential true finding.

\section{Discussion}

This systematic review of the prevalence of psychiatric morbidity associated with ADHD in prison included 18 studies comprised of 1615 individuals with ADHD and 3128 without the disorder. Subgroup analysis allowed to partial out heterogeneity due to age of participants, and its impact on the effect estimates. Several keys findings were produced from this review. First, the risk of (non-ADHD) psychopathology is significantly increased among adult prisoners with ADHD compared with prisoners without ADHD. Second, significant associations with all psychiatric morbidity categories were present in adult offenders with ADHD, but in youth offenders these were limited to mood/affective disorders, highlighting important differences by age. Third, there was greater heterogeneity in effect sizes for youth samples.

Adult prevalence estimates of psychiatric comorbidity associated with ADHD were up to $74 \%$ for SUD and lowest (29\%) for CD. However, the largest 
(a) ADHD on conduct disorder

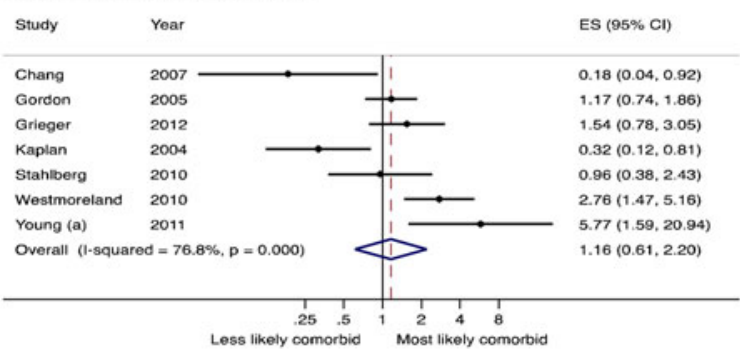

(c) ADHD on mood/affective disorders

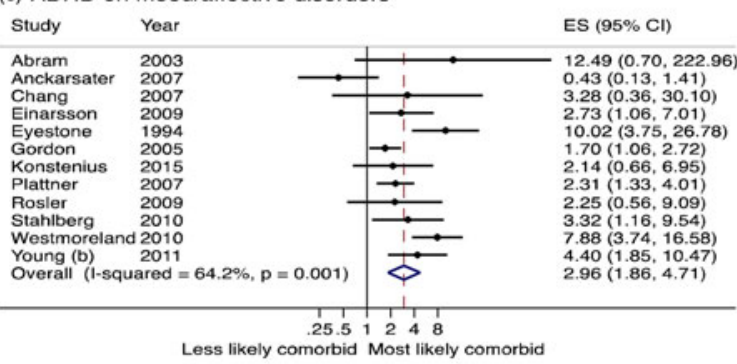

(e) ADHD on anxiety disorder

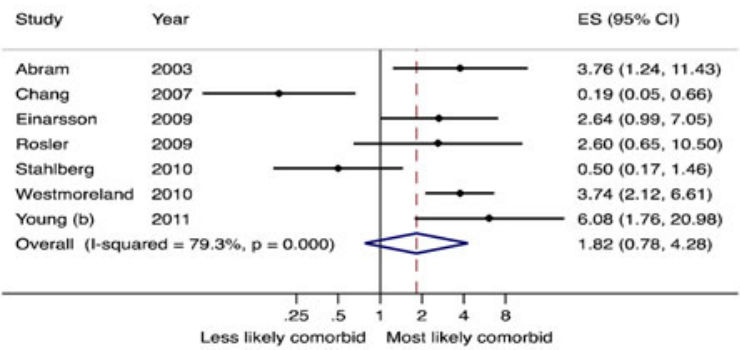

(b) $\mathrm{ADHD}$ on substance use disorders
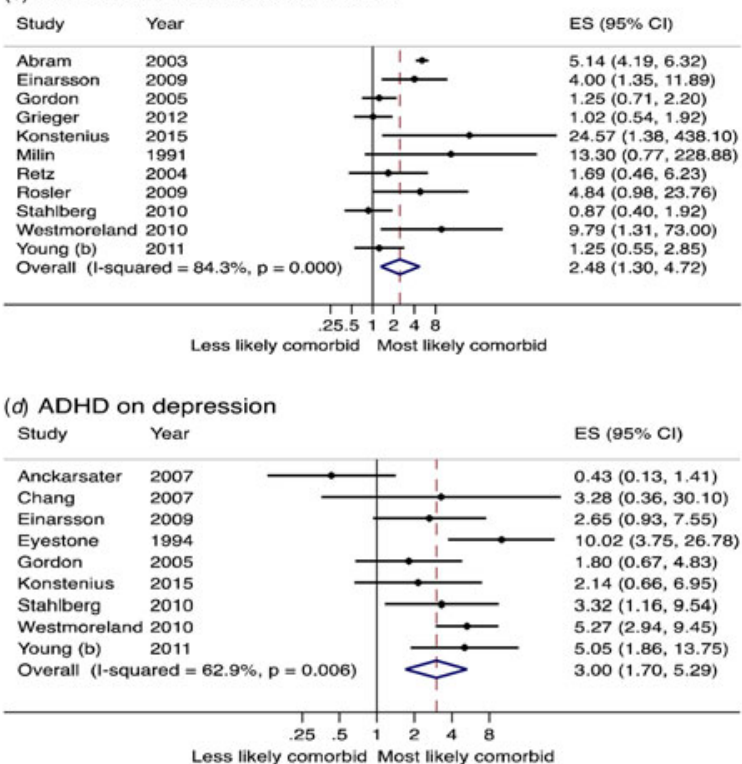

(f) ADHD on personality disorders

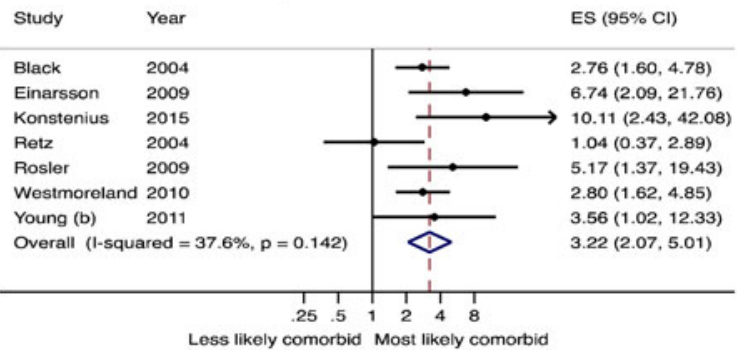

Fig. 2. Forest plots with overall odds ratios (OR), effect size (ES), and homogeneity statistics for meta-analyses of six domains of co-morbid disorders.

effect sizes measured by OR were found for mood/affective disorders with an almost 5-fold increase, and anxiety disorders with more than a 3-fold increase in the adult co-existence odds relative to non-ADHD adult prisoners. Adult ADHD prisoners were twice more likely than adult non-ADHD prisoners to have a co-morbid history of CD, SUD and PD. For youth offenders, risk was increased 3-fold for mood/affective disorders. Contrary to expectations, CD was not associated with ADHD in youth studies. This most likely reflects that $\mathrm{CD}$ is a common co-morbidity in offender samples in general and this combined problem therefore does not distinguish between prisoners with and without ADHD, e.g. the prevalence estimates by Chang et al. (2007), Stahlberg et al. (2010) and Young et al. (2011b) reported rates of CD at $75 \%, 77 \%$ and $61 \%$, respectively.

Surprisingly, there was a lack of association between ADHD and SUD in youth studies. Nevertheless, considering the exceedingly high prevalence rate of SUD in youths with ADHD (70\%), it is likely that this negative finding was due to low power to detect potential associations. The overall substantial prevalence of co-morbidity between youth and adult prisoners with ADHD, and the robust associations among adults, suggest that SUD may be an important mediator in the association between ADHD, delinquency and incarceration. Population studies indicate that $12.5 \%$ of adults meet full DSM criteria for a SUD (Kessler et al. 2006). There is evidence that untreated ADHD is a predictor for the development of SUD (Wilens et al. 1997), and pooled prevalence rates of ADHD at $23.1 \%$ have been reported among treatment seeking substance dependent patients (van Emmerik-van Oortmerssen et al. 2012). Indeed it is hypothesized that people with undiagnosed or untreated ADHD engage in substance misuse as a means of self-medication (Khantzian, 1985). The significant effect for ADHD and co-morbid mood/affective disorders (which included depression, mania and suicidal behaviour) suggests that, compared with non-ADHD peers, these youth offenders with ADHD were three times more likely to develop an affective disorder. Emotional dysregulation is increasingly recognized as a presenting problem for 

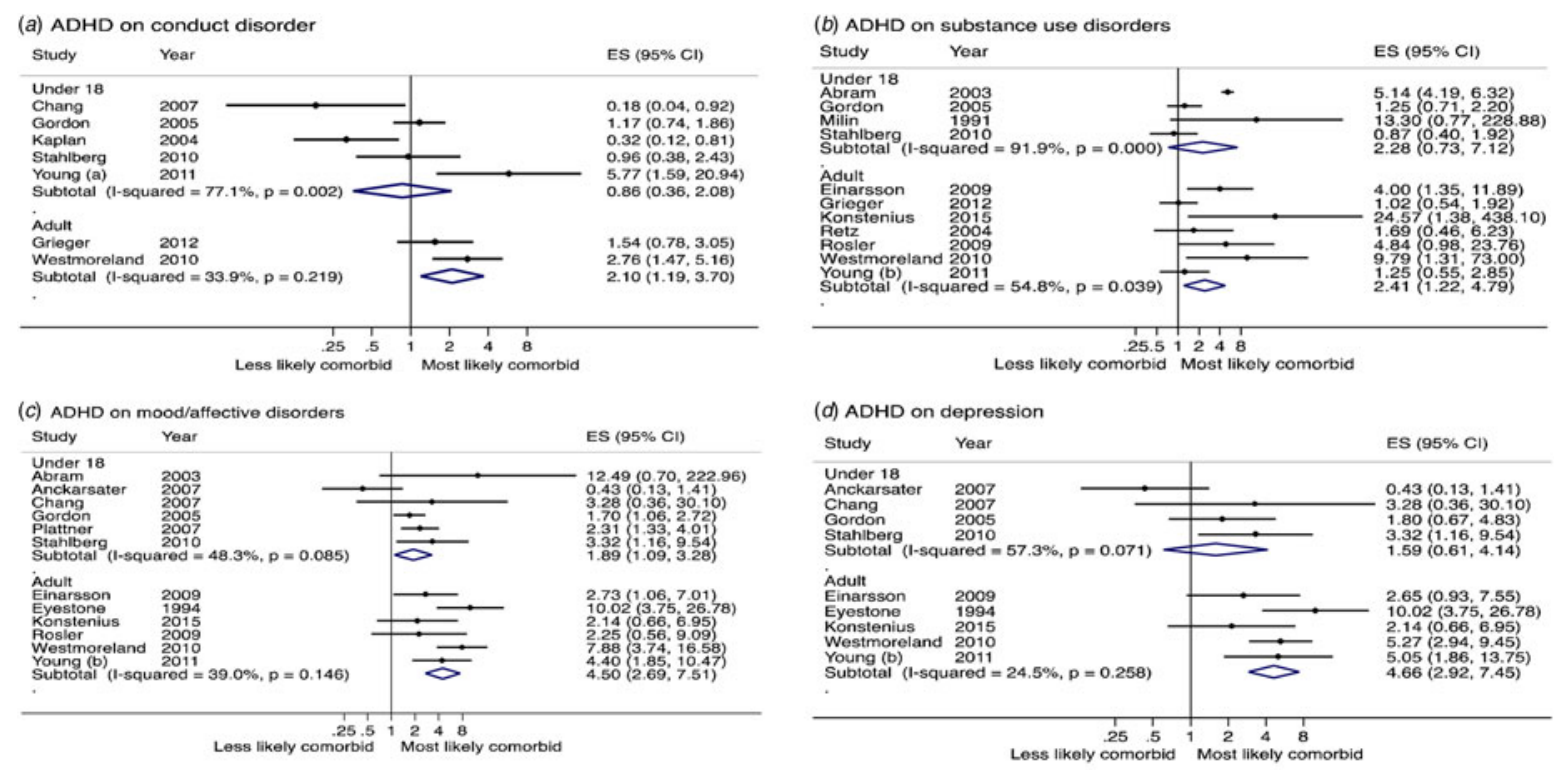

(e) ADHD on anxiety disorder

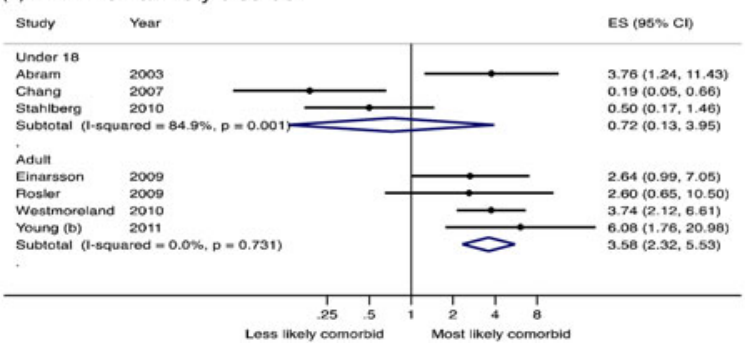

Fig. 3. Forest plots with odds ratios (OR), effect size (ES), and homogeneity statistics for meta-analyses of five domains of co-morbid disorders stratified by age $\leqslant 18$ years and adult studies. Only adult studies for personality disorders, included in Fig. 2.

adults with ADHD (Gudjonsson et al. 2013) and the pooled effects reported here suggest that emotional instability presents from childhood in young offender populations. This has implications for treatment as emotional instability, low mood and substance misuse are problems that are likely to hamper the rehabilitation process. When examining depression separately however, we found an important distinction: adult, but not youth offenders, had the greater risk (x5), which has implications for the management of risk of suicide within correctional services.

The strengths of this meta-analysis are the comprehensive review of studies and the range of psychiatric disorders studied among youth and adult offenders with and without ADHD. However, these findings should be interpreted in the context of several limitations. We found considerable variation from studies conducted in youths, and heterogeneity that was unaccounted for in some adult estimates. This may reflect variation from differences in the methodology employed in these studies, cultural differences and in instruments used for the measurement of ADHD. The latter has been found to produce important differences in meta-analytical rates (Young et al. 2014). Increased heterogeneity in minors may also reflect a process of stabilization in the characteristics of adult inmate populations over time, may be due to more similar individual 'types' being repeat offenders or some convergence of disorders with maturity. Additionally, extracted data was not sufficient to perform sensitivity analysis on potential moderators, such as gender, or to model meta-analytical regressions with sufficient power on all outcomes. For instance, limited amount of studies performed in female inmates hinders our ability to conclude whether there is an absence of gender effects on the meta-analytical regression estimates, or if we failed to attain sufficient power to detect such effects (i.e. Type II error). We established rigorous criteria for the ADHD assessment and excluded studies that only used retrospective symptom assessment, but it was not feasible to apply these same principles to the measurement of the other psychiatric categories, therefore some variation in the estimates may derive from their assessment.

This study adds to the evidence regarding the co-morbid presentation of offenders with ADHD and the findings have implications for clinical intervention and for criminal justice policy. Clinical symptoms of 
ADHD in youth and adult offenders are often missed or misdiagnosed (Baillargeon et al. 2010; Young et al. 2011c) and it seems that for youth offenders, ADHD is most likely to be misdiagnosed as mood/affective disorders. On the basis of these results, children with ADHD in prison are likely to present additional mood/affective disorders, which may manifest more recognizable symptoms, thus making it likely that an ADHD diagnosis goes unnoticed. Similar factors may be at play for adults who are likely to present with additional symptoms of mood, anxiety or substance use disorders. Research suggests that the pathway from ADHD to depression involves both anxiety and disruptive behaviour, and increases with age due to the continued negative reactions of others to their ADHD and disruptive symptoms (Roy et al. 2014). The differences between the effect estimates for youths and adults found in the present study suggest an incremental effect (in both frequency and severity) for the development of co-morbidities. It is likely that a cumulative effect of psychiatric morbidity takes its toll on the young person's social and personal development, leading them to become emotionally less resilient and increasing the risk for the development of clinical and personality co-morbid pathology as they mature.

With re-offending rates related to psychiatric co-morbidity (Baillargeon et al. 2010), the identification of effective interventions for this patient group should be a primary concern. In developmental terms, onset of ADHD symptoms most likely will onset before these co-morbid conditions, therefore primary prevention strategies targeting children at risk may help improve long-term outcomes. Further research on this area should aim to better understand the contribution of ADHD and co-existing conditions in the pathways to delinquency and crime.

\section{Acknowledgements}

We thank E. Watts (Fishawack Communications Ltd, UK, funded by Shire AG, Switzerland) and G. Stoudt (Shire, USA) for performing the initial searches; J. Wright and K. Lay (Caudex Medical, UK, funded by Shire AG, Switzerland) and K. Brown (Institute of Psychiatry, Psychology and Neuroscience, King's College London) for support with extracting relevant data from the studies. O. Sedgwick receives funding support from the National Institute for Health Research (NIHR) Mental Health Biomedical Research Centre at South London and Maudsley National Health Service (NHS) Foundation Trust and King's College London. The views expressed are those of the author(s) and not necessarily those of the NHS, the NIHR or the Department of Health. R. González was partially funded by NIDA grant 5R24DA024868-05.

\section{Declaration of interest}

S.Y. and G.G. have received honoraria for consultancy, travel, educational talks and /or research from Janssen, Eli Lilly, Shire, Novartis, HB Pharma, Flynn Pharma and/or Shire. P.H. was an employee of Shire. He is now Vice President, Global HEOR, Vertex Pharmaceuticals, USA. Shire develops and markets drugs to treat psychiatric disorders, including ADHD. M.F. is a paid statistical consultant to Shire. The other authors have no conflicts of interest.

\section{References}

Abram KM, Teplin LA, McClelland GM, Dulcan MK (2003). Comorbid psychiatric disorders in youth in juvenile detention. Archives of General Psychiatry 60, 1097-1108.

Anckarsater H, Nilsson T, Stahlberg O, Gustafson M, Saury JM, Rastam M, Gillberg C (2007). Prevalences and configurations of mental disorders among institutionalized adolescents. Developmental Neurorehabilitation 10, 57-65.

Baillargeon J, Penn JV, Knight K, Harzke AJ, Baillargeon G, Becker EA (2010). Risk of reincarceration among prisoners with co-occurring severe mental illness and substance use disorders. Administration and Policy in Mental Health and Mental Health Services 37, 367-374.

Black DW, Arndt S, Hale N, Rogerson R (2004). Use of the Mini International Neuropsychiatric Interview (MINI) as a screening tool in prisons: results of a preliminary study. Journal of the American Academy of Psychiatry and the Law 32, 158-162.

Chang HL, Chen SH, Huang C (2007). Temperament of juvenile delinquents with history of substance abuse. Chang Gung Medical Journal 30, 47-52.

DerSimonian R, Laird N (1986). Meta-analysis in clinical trials. Controlled Clinical Trials 7, 177-188.

Einarsson E, Sigurdsson JF, Gudjonsson GH, Newton AK, Bragason OO (2009). Screening for attention-deficit hyperactivity disorder and co-morbid mental disorders among prison inmates. Nordic Journal of Psychiatry 63, 361-367.

Eyestone LL, Howell RJ (1994). An epidemiological study of attention-deficit hyperactivity disorder and major depression in a male prison population. Bulletin of the American Academy of Psychiatry and the Law 22, 181-193.

Fazel S, Seewald K (2012). Severe mental illness in 33,588 prisoners worldwide: systematic review and metaregression analysis. British Journal of Psychiatry 200, 364-373.

Forehand R, Wierson M, Frame C, Kempton T, Armistead L (1991). Juvenile delinquency entry and persistence: do attention problems contribute to conduct problems? Journal of Behavior Therapy and Experimental Psychiatry 22, 261-264.

Ginsberg Y, Hirvikoski T, Grann M, Lindefors N (2012). Long-term functional outcome in adult prison inmates with ADHD receiving OROS-methylphenidate. European Archives of Psychiatry and Clinical Neuroscience 262, 705-724.

Gonzalez RA, Gudjonsson GH, Wells J, Young S (2013). The role of emotional distress and ADHD on institutional behavioral disturbance and recidivism among offenders. 
Journal of Attention Disorders. Published online: 26 July 2013. doi: $10.1177 / 1087054713493322$.

Gonzalez RA, Velez-Pastrana MC, Ruiz Varcarcel JJ, Levin FR, Albizu-Garcia CE (2015). Childhood ADHD Symptoms Are Associated With Lifetime and Current Illicit Substance-Use Disorders and In-Site Health Risk Behaviors in a Representative Sample of Latino Prison Inmates. Journal of Attention Disorders 19, 301-312.

Gordon JA, Moore PM (2005). ADHD among incarcerated youth: an investigation on the congruency with ADHD prevalence and correlates among the general population. American Journal of Criminal Justice 30, 87-97.

Grieger L, Hosser D (2012). Attention deficit hyperactivity disorder does not predict criminal recidivism in young adult offenders: results from a prospective study. International Journal of Law and Psychiatry 35, 27-34.

Gudjonsson G, Wells J, Young S (2011). Motivation for offending among prisoners and the relationship with Axis I and Axis II disorders and ADHD symptoms. Personality and Individual Differences 50, 64-68.

Gudjonsson G, Wells J, Young S (2012). Personality disorders and clinical syndromes in ADHD prisoners. Journal of Attention Disorders 16, 304-313.

Gudjonsson GH, Sigurdsson JF, Adalsteinsson TF, Young S (2013). The relationship between ADHD symptoms, mood instability, and self-reported offending. Journal of Attention Disorders 17, 339-346.

Higgins JP, Thompson SG (2002). Quantifying heterogeneity in a meta-analysis. Statistics in Medicine 21, 1539-1558.

Kaplan SG, Cornell DG (2004). Psychopathy and ADHD in adolescent male offenders. Youth Violence and Juvenile Justice 2, 148-160.

Kessler RC, Adler L, Barkley R, Biederman J, Conners CK, Demler O, Faraone SV, Greenhill LL, Howes MJ, Secnik K, Spencer T, Ustun TB, Walters EE, Zaslavsky AM (2006). The prevalence and correlates of adult ADHD in the United States: results from the National Comorbidity Survey Replication. American Journal of Psychiatry 163, 716-723.

Khantzian EJ (1985). The self-medication hypothesis of addictive disorders: focus on heroin and cocaine dependence. American Journal of Psychiatry 142, 1259-1264.

Konstenius M, Larsson H, Lundholm L, Philips B, van de Glind G, Jayaram-Lindstrom N, Franck J (2015). An epidemiological study of ADHD, substance use, and comorbid problems in incarcerated women in Sweden. Journal of Attention Disorders 19, 44-52.

Langley K, Fowler T, Ford T, Thapar AK, van den Bree M, Harold G, Owen MJ, O'Donovan MC, Thapar A (2010). Adolescent clinical outcomes for young people with attention-deficit hyperactivity disorder. British Journal of Psychiatry 196, 235-240.

Liberati A, Altman DG, Tetzlaff J, Mulrow C, Gotzsche PC, Ioannidis JP, Clarke M, Devereaux PJ, Kleijnen J, Moher D (2009). The PRISMA statement for reporting systematic reviews and meta-analyses of studies that evaluate health care interventions: explanation and elaboration. PLoS Medicine 6, e1000100.
Lichtenstein P, Halldner L, Zetterqvist J, Sjolander A, Serlachius E, Fazel S, Langstrom N, Larsson H (2012). Medication for attention deficit-hyperactivity disorder and criminality. New England Journal of Medicine 367, 2006-2014.

Milin R, Halikas JA, Meller JE, Morse C (1991). Psychopathology among substance abusing juvenile offenders. Journal of the American Academy of Child and Adolescent Psychiatry 30, 569-574.

Plattner B, The SS, Kraemer HC, Williams RP, Bauer SM, Kindler J, Feucht M, Friedrich MH, Steiner H (2007). Suicidality, psychopathology, and gender in incarcerated adolescents in Austria. Journal of Clinical Psychiatry 68, 1593-1600.

Pliszka SR (1998). Comorbidity of attention-deficit/ hyperactivity disorder with psychiatric disorder: an overview. Journal of Clinical Psychiatry 59 (Suppl 7), 50-58.

Polanczyk G, de Lima MS, Horta BL, Biederman J, Rohde LA (2007). The worldwide prevalence of ADHD: a systematic review and metaregression analysis. American Journal of Psychiatry 164, 942-948.

Retz W, Retz-Junginger $P$, Hengesch G, Schneider M, Thome J, Pajonk FG, Salahi-Disfan A, Rees O, Wender PH, Rosler M (2004). Psychometric and psychopathological characterization of young male prison inmates with and without attention deficit/hyperactivity disorder. European Archives of Psychiatry and Clinical Neuroscience 254, 201-208.

Rosler M, Retz W, Retz-Junginger P, Hengesch G, Schneider M, Supprian T, Schwitzgebel P, Pinhard K, Dovi-Akue N, Wender P, Thome J (2004). Prevalence of attention deficit-/ hyperactivity disorder (ADHD) and comorbid disorders in young male prison inmates. European Archives of Psychiatry and Clinical Neuroscience 254, 365-371.

Rosler M, Retz W, Yaqoobi K, Burg E, Retz-Junginger P (2009). Attention deficit/hyperactivity disorder in female offenders: prevalence, psychiatric comorbidity and psychosocial implications. European Archives of Psychiatry and Clinical Neuroscience 259, 98-105.

Roy A, Oldehinkel AJ, Verhulst FC, Ormel J, Hartman CA (2014). Anxiety and disruptive behavior mediate pathways from attention-deficit/hyperactivity disorder to depression. Journal of Clinical Psychiatry 75, e108-e113.

Seixas M, Weiss M, Muller U (2012). Systematic review of national and international guidelines on attention-deficit hyperactivity disorder. Journal of Psychopharmacology 26, 753-765.

Shaw M, Hodgkins P, Caci H, Young S, Kahle J, Woods AG, Arnold LE (2012). A systematic review and analysis of long-term outcomes in attention deficit hyperactivity disorder: effects of treatment and non-treatment. BMC Medicine 10, 99.

Simon V, Czobor P, Balint S, Meszaros A, Bitter I (2009). Prevalence and correlates of adult attention-deficit hyperactivity disorder: meta-analysis. British Journal of Psychiatry 194, 204-211.

Stahlberg O, Anckarsater H, Nilsson T (2010). Mental health problems in youths committed to juvenile institutions: prevalences and treatment needs. European Child and Adolescent Psychiatry 19, 893-903. 
van Emmerik-van Oortmerssen $K$, van de Glind G, van den Brink W, Smit F, Crunelle CL, Swets M, Schoevers RA

(2012). Prevalence of attention-deficit hyperactivity disorder in substance use disorder patients: a meta-analysis and meta-regression analysis. Drug and Alcohol Dependence 122, 11-19.

Westmoreland P, Gunter T, Loveless P, Allen J, Sieleni B, Black DW (2010). Attention deficit hyperactivity disorder in men and women newly committed to prison: clinical characteristics, psychiatric comorbidity, and quality of life. International Journal of Offender Therapy and Comparative Criminology 54, 361-377.

Wilens TE, Biederman J, Mick E, Faraone SV, Spencer T (1997). Attention deficit hyperactivity disorder (ADHD) is associated with early onset substance use disorders. Journal of Nervous and Mental Disease 185, 475-482.

Young S, Gudjonsson GH, Wells J, Asherson P, Theobald D, Oliver B, Scott C, Mooney A (2009). Attention deficit hyperactivity disorder and critical incidents in a Scottish prison population. Personality and Individual Differences 46, 265-269.

Young S, Misch P, Collins P, Gudjonsson G (2011a). Predictors of institutional behavioural disturbance and offending in the community among young offenders. Journal of Forensic Psychiatry and Psychology 22, 72-86.

Young S, Moss D, Sedgwick O, Fridman M, Hodgkins P (2014). A meta-analysis of the prevalence of attention deficit hyperactivity disorder in incarcerated populations. Psychological Medicine 45, 247-258.

Young S, Wells J, Gudjonsson GH (2011b). Predictors of offending among prisoners: the role of attention-deficit hyperactivity disorder and substance use. Journal of Psychopharmacology 25, 1524-1532.

Young SJ, Adamou M, Bolea B, Gudjonsson G, Muller U, Pitts M, Thome J, Asherson P (2011c). The identification and management of ADHD offenders within the criminal justice system: a consensus statement from the UK Adult ADHD Network and criminal justice agencies. BMC Psychiatry 11, 32. 